\title{
Einstein's witches' sabbath: the first Solvay council on physics
}

- Frits Berends - professor of theoretical physics emeritus, Universiteit Leiden - the Netherlands - DOI: 10.1051/epn/2011502

- Franklin Lambert - professor of theoretical physics emeritus, Vrije Universiteit Brussel and Solvay Institutes - Belgium

\section{One hundred years ago, on 29 October 1911, a very special event took place in Brussels: the opening of the first Solvay Council, a meeting which would become a milestone in the history of modern physics.}

I

n mid-June 1911, invitations were sent to 23 prominent physicists to take part in a 'Conseil scientifique international'. Its aim was to 'elucidate some actual problems regarding the molecular and kinetic theories'. The confidential letter, signed by Ernest Solvay (1838-1922) - a wealthy Belgian industrialist and scientific philanthropist - stressed that the existing theories could not account for the observed properties of radiation and specific heats. It recalled that Planck and Einstein had shown that the contradictions between theory and experiment could be solved by imposing limitations to the motion of electrons and atoms, an assumption requiring a fundamental revision of current theories. The meeting was said to be convened in the hope that it would pave the way to a solution to the problem. Eight subjects were to be discussed under the chairmanship of Hendrik Antoon Lorentz (1853-1928). The names of the invited members were listed. Replies to the invitation were to be sent to Prof. Dr. W.Nernst in Berlin.

\section{What was so special about this letter?}

An international conference on physics was most unusual. Only one had taken place before: the 1900 Conference in Paris, with 750 participants from 24 countries, which had been convened by the French Physical Society, not by an international physics organization - as none existed.

Yet, more things were special. Among the invited members only four had been previously informed. The others must have been puzzled. What was so critical in physics? Why this sudden concern? Why Brussels, if no Belgian physicists were involved? What would be the outcome of such a 'summit'? Why was it called by Solvay, and what about Nernst? These questions are still relevant today. This note will try to answer them.

\section{The quantum theory between 1900 and 1910}

In spite of its success, Planck's result on black-body radiation in 1900 did not attract much attention. Its derivation remained a matter of discussion between a few experts, including Lorentz. How essential was the assumption that Planck's oscillators could only absorb and emit energy by indivisible 'units' (quanta)?

In 1903, Lorentz showed that the electron theory could only account for the long-wave behaviour of Planck's formula, in accordance with what Rayleigh had deduced from the equipartition theorem - a result also obtained by Jeans and by Einstein in 1905 .

Starting from Wien's radiation formula, which accounted for the short-wave regime, Einstein was led in 1905 to the formulation of his revolutionary concept of light quanta, a heuristic view which provided a simple description of the photoelectric effect. In 1907 Einstein applied quantum ideas to matter, treating the oscillating atoms in a solid as Planck-oscillators. He thus obtained a specific heat formula which explained the observed deviations from the classical law of Dulong-Petit.

This was the state of the art in the early quantum theory [1], when the physical-chemist Walther Nernst (18641941) entered the field.

\section{Nernst discovers Einstein}

Late in 1905 Nernst announced his 'heat theorem, or the 'third law of thermodynamics', a bold proposition with far-reaching implications. It predicted a decrease of specific heats with temperature, and their convergence

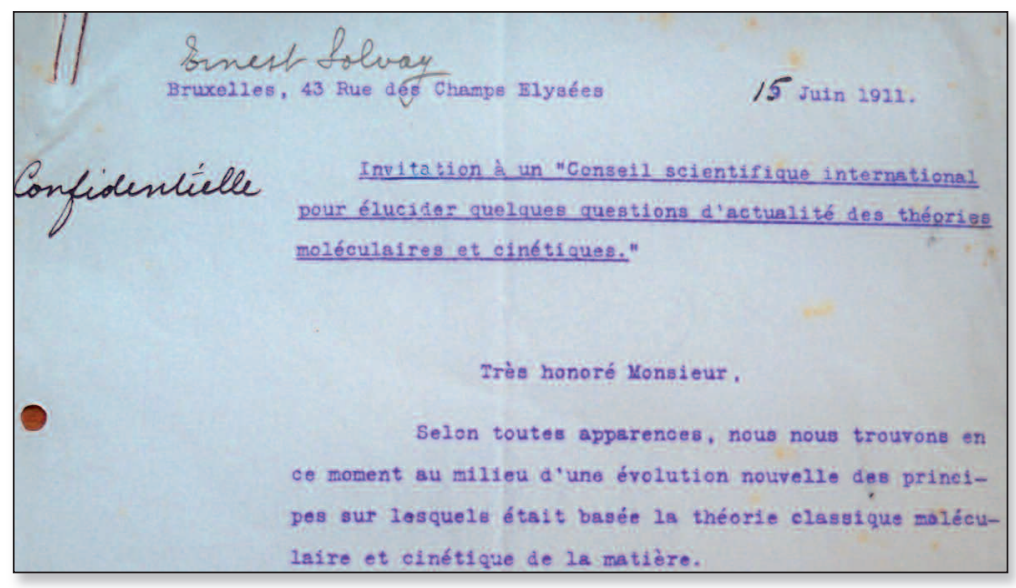


- FIG. 2:

Topics for the first

Council, as listed

in the letter of

invitation,

NHA, Archive

H.A. Lorentz,

inv.nr. 73. The

corresponding

rapporteurs are

listed in our text

in the order of

these eight top-

ics. Experimenta

topics on black-

body radiation

covered by

Warburg and

Rubens are not

yet mentioned.

The same holds

for magnetism,

Langevin's topic

V FIG. 3:

Group picture of

the second Solvay

Council'Structure

de la Matière'

in the Solvay

Institute of

Physiology,

october 1913

reproduced with

permission of the

International

Solvay Institutes

for Physics and

Chemistry,

founded by

E. Solvay, Brussels.

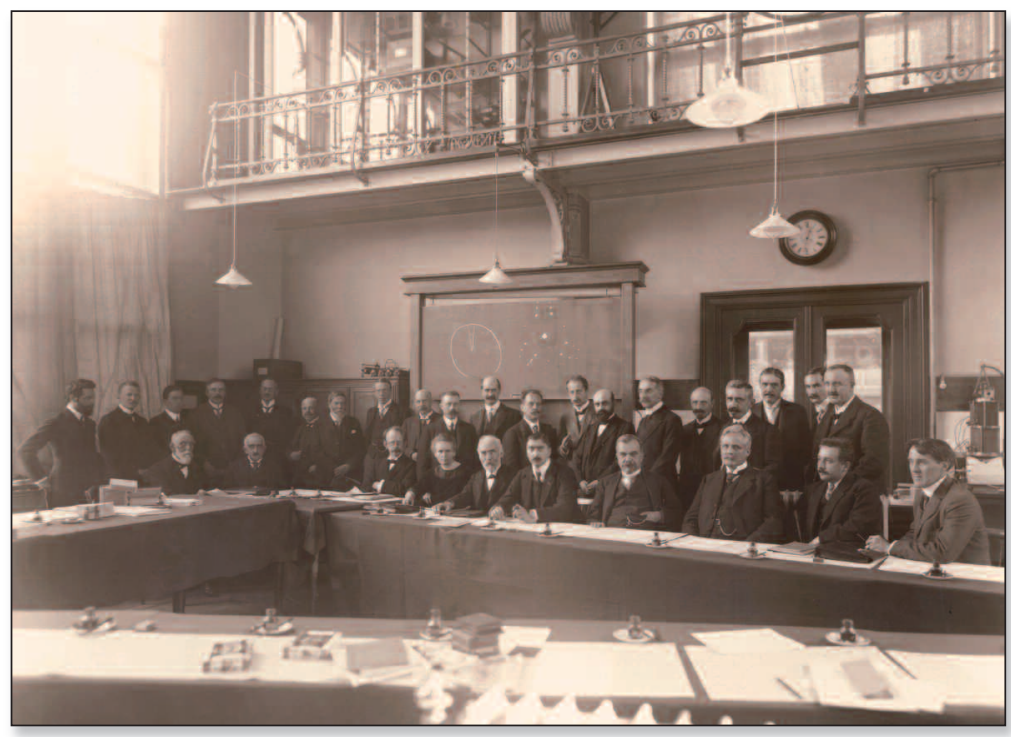

then it will remain for all times a 'beautiful memory"'. On 1 April Nernst spoke in Paris, about his theorem, the results of his measurements and their agreement with Einstein's formula [3]. Stimulated by his findings and by his foreign contacts, Nernst conceived the idea of organizing a 'Konzil' on quanta, a 'summit', in other words a 'Concile' or 'Conseill.

\section{Nernst's plan for a Konzil}

Nernst discussed his idea with Planck, Knudsen and Lorentz. They agreed to participate, but Planck preferred to wait one more year for the emergence of new elements that would even increase the crisis. He also expressed concern about the proposed list of participants, indicating that most of them would not be seriously interested in the subject. In spite of this, Nernst decided to go ahead with the help of his Belgian collaborator Goldschmidt, a chemist, an inventor and a personal acquaintance of Solvay.

Early in July 1910 Nernst met the industrialist at Goldschmidt's home in Brussels. Later that month he submitted a detailed proposal for a Konzil, asking Solvay to throw it in the waste-paper basket in case of disapproval. The proposal contained a letter of invitation which Solvay only needed to sign.

Nernst also insisted for not being named as the initiator of the project. He was obviously eager to have the quantum theory discussed by internationally recognized authorities, brought together on neutral ground by a fair-minded patron of science. Brussels seemed therefore perfectly suited. Solvay accepted the proposal, but asked for some deferment. Meanwhile, several alterations were made in the list of invited members and in the Council's chairmanship. For instance, Solvay wanted to have a balance between the numbers of German, French and British participants. When Lorentz became the chairman, in May 1911, he arranged for Kamerlingh Onnes to be invited.

Why did Nernst's name show up on the letter of invitation? Quite simply because Goldschmidt left for the Congo, in June 1911, to set up wireless telegraphy, at King Albert's request. The irritated Nernst had no other choice than to take care himself of the correspondence.

\section{The Council in hotel Métropole}

Among the 23 invited members, five chose to stand aside: Larmor, Lord Rayleigh, Schuster, Thomson and Van der Waals. Goldschmidt, M.de Broglie and Lindemann, Nernst's British collaborator, acted as secretaries. Opening speeches were delivered by Solvay, Lorentz and Nernst. 11 reports and a letter from Rayleigh were discussed, five on black-body radiation and six on the properties of matter. The rapporteurs were: Lorentz, Knudsen, Perrin, Jeans, Planck, Einstein, Sommerfeld, Nernst, Warburg, Rubens and Langevin. The proceedings appeared in 1912 under the title 'The Theory of Radiation 
and the Quanta. Kamerlingh Onnes's contribution on the discovery of superconductivity was based on what he had said during the discussion of Nernst's report. Rutherford did not mention his remarkable alpha-scattering results, notwithstanding the fact that atomic models were discussed during the reports of Planck and Sommerfeld. The other participants were M.Brillouin, M.Curie, Hasenöhrl, Poincaré and Wien.

The meeting was described by several participants. Einstein joked, in letters [4] to his friends, about the 'witches' sabbath' which would have been a delight to diabolic Jesuit fathers'. Brillouin reported [5] on the atmosphere during the long discussions which took place in the overheated little room of hotel Métropole. He described Lorentz' brilliant performance as chairman and translator, who used his wonderful tact and intelligence to intervene whenever a clarification was needed, and who managed to summarize the outcome of the many discussions.

\section{Consequences of the Council}

The Brussels meeting was rich in consequences. It made a large group of scientists aware of the importance of quantum problems. One member, Poincaré, produced a proof that Planck's law was bound to introduce an essential quantum discontinuity. This had a decisive influence on Jeans [6]. As he visited Manchester Bohr was told by Rutherford of the Solvay Council discussions [7]. In 1913, he used Planck's quantum of action with success. Louis de Broglie's enthusiasm for quanta was aroused by his reading of the Council's minutes which had been noted by his brother Maurice.

The Solvay Council had also a major impact on Einstein's academic career. His move in 1912 from Prague to the ETH in Zürich was made easier by M.Curie's and Poincaré's strong recommendations, which were sent shortly after the conference. The next step, which brought him to Berlin, as a member of the Prussian Academy, took place in 1913, when the four Berliners from the Solvay Council signed the pivotal election proposal.

\section{Institut international de physique Solvay}

The origin of the Council's most remarkable achievement - the founding by Solvay of the International Institute of Physics in May 1912 - was a private meeting on the last day of the conference, at which Solvay, Lorentz and some members discussed experiments for which Solvay would provide the necessary means. Lorentz was asked to work out a plan for an international institute. On 4 January, he presented his concept of the institute. Solvay agreed with it, in principle, and sent one of his co-workers to Leiden to draw up the statutes.

The Institute's main purpose was to stimulate research in physics at an international level, by means of grants. Regular Councils would be organized, and young Belgians would get travelling scholarships. The grants would go to researchers selected by an international committee, chaired by Lorentz. A local committee would take care of the budget, the scholarships and the administration.

Research subsidies were granted until the outbreak of WWI. Among the 40 beneficiaries, six would get a Nobel Prize: von Laue, W. L. Bragg, Barkla, Stark, Franck and Hertz. Moseley, who also obtained support, was nominated in 1915 for the Prize but died on the battle field near Gallipoli.

The war gave rise to a lot of bitterness, and led to the isolation of the Austro-German scientists. In spite of Lorentz' efforts to achieve international reconciliation, it was only in 1926 that experts from all countries could be invited in contrast to the third and fourth Councils. So it was not until the fifth Solvay Council in 1927 that most key-developers of quantum mechanics gathered in Brussels.

\section{References}

[1] T.S. Kuhn, Black-Body Theory and the Quantum Discontinuity, 1894-1912, The University of Chicago Press, Chicago (1978).

[2] Diana Kormos Barkan, Science in Context 6 (1993) 62.

[3] W. Nernst, Journal de Physique, 4e Série, IX (1910) 48.

[4] Letters 299, 303 en 305 in The collected papers of Albert Einstein, Vol.5, correspondence 1902-1914, eds. M.J.Klein, A.J.Kox, R. Schulmann, Princeton University Press, Princeton (1993).

[5] M. Brillouin, Physica 6 (1925) 30.

[6] Russell McCormmach, Henri Poincaré and the Quantum Theory, Isis 58 (1967) 37.

[7] N.Bohr, Essays 1958-1962 on Atomic Physics and Human Knowledge (1963) 31.

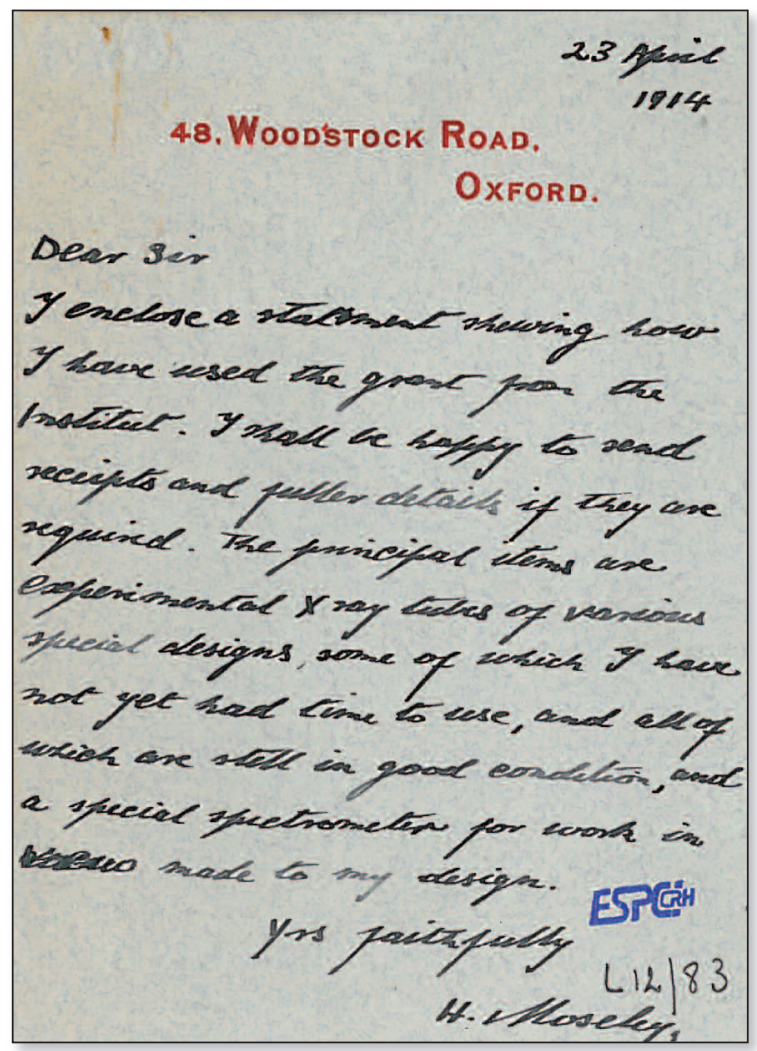

4 FIG. 4

Moseley's explanatory note which specifies the spending of his grant, Archive Centre de ressources historiques de I'ESPCI ParisTech, document L12/83. 